\title{
Usefulness of colonoscopy in ischemic colitis
}

\author{
M. Lozano-Maya, A. Ponferrada-Díaz, C. González-Asanza, O. Nogales-Rincón, C. Senent-Sánchez, \\ V. Pérez-de-Ayala, P. Jiménez-Aleixandre, E. Cos-Arregui and P. Menchén-Fernández-Pacheco \\ Service of Digestive Diseases. Section of Digestive Endoscopy. Hospital General Universitario Gregorio Marañón. \\ Madrid, Spain
}

\begin{abstract}
Background: the ischemic colitis is intestinal the most frequent cause of ischemia. With this work we determine the demographic and clinical characteristics, and the usefulness of the colonoscopy in the patients with ischemic colitis diagnosed in our centre in relation to a change of therapeutic attitude.

Method: retrospective study in which were selected 112 patients diagnosed with ischemic colitis by colonoscopy and biopsy, in a period of five years. It was analyzed: age, sex, reason for examination, factors of cardiovascular risk, endoscopic degree of ischemia, change in the therapeutic attitude, treatment and outcome.

Results: the average age was of $73.64 \pm 12.10$ years with an equal incidence in women (50.9\%) and the men (49.1\%). The associated factors were the HTA (61.1\%), tobacco (37.2\%) and antecedents of cardiovascular episode (52.2\%). The most frequent reason for colonoscopy was rectorrhagia (53.6\%) followed of the abdominal pain (30.4\%), being urgent the 65.3\%. Colonoscopy allowed a change in the therapeutic attitude in the 50 increasing in the urgent one to the $65.75 \%$. Global mortality was of $27.67 \%$. The serious ischemic colitis $(25 \%)$ was more frequent in men $(64.3 \%)$ in urgent indication $(85.71 \%)$ and attends with high mortality (53.57\%). Surgical treatment in the $57.14 \%$ was made with a good evolution in the $50 \%$, whereas the patients with mild or moderate ischemic colitis had a better prognosis (favourable evolution in $80.95 \%$ ) with smaller requirement of the surgical treatment (4.76\%), $\mathrm{p}<0.05$.

Conclusion: the colitis ischemic are more frequent in the older age. The most frequent symptoms are the rectorrhagia and the abdominal pain. The colonoscopy is a useful technique to evaluate the gravity and it induces a change of attitude according to the result of the same one. The evidence of a serious colitis supposed an increase of the necessity of surgery and worse prognosis.
\end{abstract}

Key words: Colitis. Colonoscopy. Ischemia.

Received: $30-12-08$

Accepted: 26-01-10.

Correspondence: Mar Lozano Maya. Servicio de Aparato Digestivo. Hospital General Universitario Gregorio Marañón. C/ Doctor Esquerdo, 46. 28007 Madrid, Spain.e-mail: marlmaya@hotmail.com

\section{RESUMEN}

Introducción: la colitis isquémica es la causa más frecuente de isquemia intestinal. Realizamos un estudio con el objetivo de analizar las características demográficas, clínicas y la utilidad de la colonoscopia en los pacientes diagnosticados de colitis isquémica en nuestro centro en relación a un cambio de actitud terapéutica.

Método: estudio retrospectivo en el que se seleccionaron 112 pacientes diagnosticados de colitis isquémica mediante colonoscopia y biopsia, en un periodo de tiempo de cinco años. Se analizaron: edad, sexo, motivo de exploración, factores de riesgo cardiovascular, grado endoscópico de isquemia, cambio en la actitud terapéutica, tratamiento y evolución.

Resultados: la edad media de nuestros pacientes fue de 73,6 $\pm 12,1$ años con una incidencia similar en ambos sexos $(50,9 \%$ mujeres y $49,1 \%$ hombres). Los factores de riesgo asociados fueron la hipertensión arterial $(61,1 \%)$, el tabaco $(37,2 \%)$ y antecedente de accidente cardiovascular previo (52,2\%). El motivo más frecuente de realización de colonoscopia fue rectorragia $(53,6 \%)$ seguido de dolor abdominal $(30,4 \%)$, realizándose de forma urgente en el 65,3\% de los casos. La colonoscopia permitió un cambio en la actitud terapéutica en el 50\% de los casos, aumentando en la urgente al 65,75\%. La mortalidad global fue del $27,67 \%$. La colitis isquémica grave (25\%) fue más frecuente en varones $(64,3 \%)$, y cuando la indicación de colonoscopia fue urgente $(85,71 \%)$ y cursó con mortalidad alta $(53,57 \%)$. En estos se realizó tratamiento quirúrgico en el 57,14\% de los casos con una evolución favorable en el 50\%, mientras que los pacientes con colitis isquémica leve o moderada tuvieron un pronóstico mejor, con evolución favorable en el $80,95 \%$ de los casos y con menor requerimiento de tratamiento quirúrgico $(4,76 \%, p<0,05)$.

Conclusión: la colitis isquémica es más frecuente en la edad avanzada. La sintomatología más común es la rectorragia y el dolor abdominal. La colonoscopia permite evaluar la gravedad $e$ induce un cambio de actitud según el resultado de la misma. La evidencia de una colitis grave supuso un aumento de la necesidad de cirugía y peor pronóstico.

Palabras clave: Colitis. Colonoscopia. Isquemia.

Lozano-Maya M, Ponferrada-Díaz A, González-Asanza C, Nogales-Rincón O, Senent-Sánchez C, Pérez-de-Ayala V, JiménezAleixandre P, Cos-Arregui E, Menchén-Fernández-Pacheco P. Utility of colonoscopy in ischemic colitis . Rev Esp Enferm Dig 2010; 102: 478-483. 


\section{INTRODUCTION}

Ischemic colitis (IC) is the most common cause of intestinal ischemia. It has an incidence on our environment between 16-20 cases per 100,000 population per year (1). Normally it is underestimated by the existence of cases by few symptoms. There are several risk factors that must be born in mind to establish a rapid diagnosis of suspicion (2-12). Most frequent location is the left colon, fundamentally splenic flexure and rectosigmoid junction. Most frequent symptom is abdominal pain with rectal bleeding or hematochezia (13). There are two types of IC: the not gangrenous IC, more frequent (80-85\%), and the gangrenous IC. The first one can be treated conservatively with hemodynamic stabilization, intravenous fluids and antibiotics. The second one needs urgent surgery to remove the nonviable colonic mucosa (14-16). The main diagnostic method is colonoscopy with biopsy, being the most profitable exploration (17-22). The presence of endoscopic signs of transmural necrosis establishes the need for urgent surgery.

We realize a study with the aim to analyze the demographic and clinical characteristics and the usefulness of the colonoscopy in the patients with IC diagnosed in our center in relation to a change of therapeutic attitude.

\section{METHODS}

We have realized a retrospective study of the colonoscopies performed in our center during a period of 5 years. One hundred twelve patients diagnosed with ischemic colitis were included of a total of 24,144 patients with colonoscopy from the $1^{\text {st }}$ January 2001 to the $31^{\text {st }}$ December 2006. We included patients with probable diagnosis of IC (26\%) based on clinical and endoscopic criteria or definitive diagnosis (74\%) with histological confirmation according to the criteria of Brandt (Table I).

Colonoscopy was performed with an urgent indication in most cases $(65.3 \%)$, making it within 24 hours from the onset of symptoms in those patients with severe lower gastrointestinal bleeding and clinical and radiological suspicion of ischemic colitis. Colonoscopy was complete

Table I. Brandt criteria for diagnosis of ischemic colitis

\begin{tabular}{lccc}
\hline Diagnosis & Symptoms & Colonoscopy & Histology \\
\hline $\begin{array}{lccc}\text { Definitive } \\
\text { Probable }\end{array}$ & + & + & + \\
Possible & + & + & $\begin{array}{c}\text { Negative or not } \\
\text { performed }>24 \text { hours } \\
\text { Negative or not } \\
\text { performed }>24 \text { hours }\end{array}$ \\
\hline
\end{tabular}

in $38 \%$ of cases and incompleted in $62 \%$ to avoid iatrogenic complications.

Analyzed variables were age, sex, indication of exploration (rectal bleeding, abdominal pain, diarrhea, unexplained postoperative fever from other causes, anemia), cardiovascular risk factors (hypertension, diabetes mellitus, dyslipidemia, tobacco abuse and previous cardiovascular event), history of recent cardiovascular surgery (performed in the seven days prior to colonoscopy), endoscopic degree of ischemia as ranked by Toursarkissian and Thompson scale (Table II), therapeutic impact after exploration (understanding this as if you changed the idea of medical treatment before and after the colonoscopy, for example if it was begun antibiotic treatment and fluid not previously started after colonoscopy or if it performed surgical treatment because of endoscopic findings), treatment and outcome.

Qualitative variables were expressed as percentage and compared by chi-square test. For the analysis of quantitative variables, we used Student t-test. Subsequently, multivariate analysis was performed using logistic regression after categorizing the variables that were significant in univariate analysis to identify risk factors associated with mortality. It was considered statistically significant at $p<0.05$. Statistical software SPSS 10.0 was used to analyze data.

Table II. Endoscopic classification and clinical course of ischemic colitis. Toursarkissian \& Thompson

1. Acute (less than 20 days)

- Mild ecchymosis, petechiae and mucosal erosions less than $1 \mathrm{~cm}$ in diameter

- Moderate: the submucosal hematoma. Ulceration of the mucosa and submucosa with exposed muscle

- Severe: grayish membrane that involve the entire circumference

2. Chronic (more than 20 days)

- Chronic ulcer with granulation tissue and pseudopolyps

- Stenosis

\section{RESULTS (Table III)}

Average age was $73.6 \pm 12.1$ (24-94) years. Incidence was similar in men $(49.1 \%)$ and women $(50.9 \%)$. The main reasons for testing (Fig. 1) were rectal bleeding in $56.25 \%$ of cases and abdominal pain in $33.04 \%$. Other less frequent symptoms were diarrhea in $5.35 \%$, anemia in $3.57 \%$ and postoperative fever in $1.78 \%$.

Of all patients, $22.3 \%$ had a history of recent cardiovascular surgery. $16.96 \%$ of patients had been surgery that required aortic vascular clamping: 13 patients $(11.6 \%)$ of abdominal aortic aneurysm and 6 patients $(5.35 \%)$ of aorto-femoral bypass. 
Table III. Patients features included

\begin{tabular}{lc}
\hline Age [years; mean (SD)] & $73.6(12.1)$ \\
Male/Female [n, (\%)] & $55(49.1 \%) / 57(50.9 \%)$ \\
Arterial hypertension [n, (\%)] & $69(61.1 \%)$ \\
Diabetes mellitus [n, (\%)] & $30(26.5 \%)$ \\
Dyslipemia [n, (\%)] & $25(22.1 \%)$ \\
Tobacco abuse [n, (\%)] & $42(37.2 \%)$ \\
Prior cardiovascular stroke [n, (\%)] & $59(52.2 \%)$ \\
Prior cardiovascular surgery [n, (\%)] & $25(22.3 \%)$ \\
Rectorrhagia [n, (\%)] & $63(56.25 \%)$ \\
Abdominal pain [n, (\%)] & $37(33.04 \%)$ \\
Diarrhea [n, (\%)] & $6(5.35 \%)$ \\
Anemia [n, (\%)] & $4(3.57 \%)$ \\
Postsurgery fever [n, (\%)] & $2(1.78 \%)$ \\
Mild ischemic colitis [n, (\%)] & $42(37.5 \%)$ \\
Moderate ischemic colitis [n, (\%)] & $42(37.5 \%)$ \\
Severe ischemic colitis [n, (\%)] & $28(25 \%)$ \\
Urgent colonoscopy [n, (\%)] & $73(65.3 \%)$ \\
Treatment changed in urgent colonoscopy & \\
[n, (\%)] & $48(65.75 \%)$ \\
Surgical treatment [n, (\%)] & $20(17.85 \%)$ \\
Global mortality [n, (\%)] & $31(27.67 \%$ \\
Severe IC mortality [n, (\%)] & $15(53.57 \%)$ \\
\hline
\end{tabular}

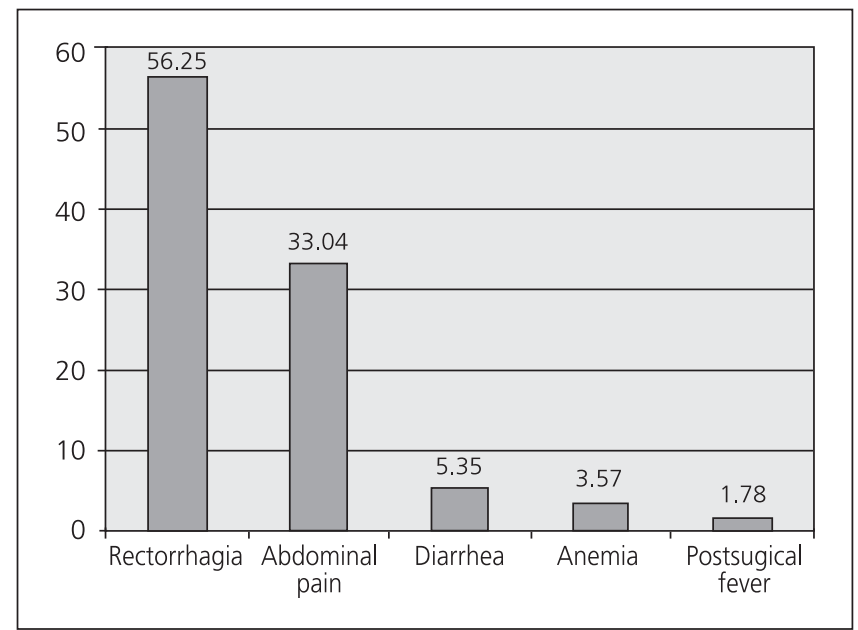

Fig. 1. Main reason for study (in percentages).

Indication of colonoscopy was urgent in most cases (n $=73 ; 65.3 \%$ ).

The cardiovascular risk factors in our patients (Fig. 2) were hypertension $(\mathrm{n}=69,61.1 \%)$, tobacco abuse $(37.2 \%)$, history of cardiovascular stroke $(52.2 \%)$, diabetes mellitus (26.5\%), and dyslipidemia $(22.1 \%)$.

According to the endoscopic Toursarkissian scale, $37.5 \%$ of patients were diagnosed with mild IC, $37.5 \%$ with moderate IC and 25\% with severe IC (Table II).

Colonoscopy caused a change in therapeutic attitude (starting medical additional treatment or surgery) in 50\% of cases, particularly when the indication of colonoscopy

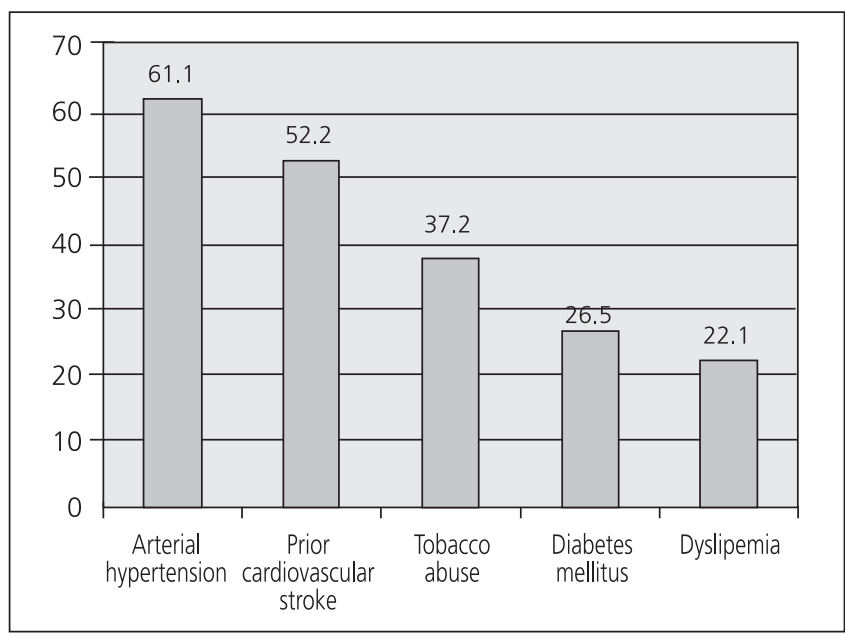

Fig. 2. Cardiovascular risk factors (in percentage).

was urgent, in which cases this change increased to $65.75 \%$.

The type of treatment performed was conservative (intravenous liquids and antibiotics) in $82.14 \%$ of cases and surgical in $17.85 \%$.

Severe IC was more frequent in males $(64.3 \%)$, and when the colonoscopy indication was urgent $(85.71 \%)$. Also we found that the severe IC had high mortality $(53.57 \%)$. In these patients, surgical treatment was performed in $57.14 \%$, with good outcome in $50 \%$. Mild or moderate IC patients $(75 \%)$ had a better outcome $(80.95 \%)$ and a lower need for surgical treatment $(4.76 \%$; $\mathrm{p}<0.05)$.

On univariate analysis we observed that neither sex nor any risk factors (hypertension, diabetes mellitus, dyslipidemia, tobacco abuse and prior cardiovascular events) were associated with the need for surgical treatment. In urgent indication for colonoscopy, there is greater need for surgical treatment than non-urgent indication -20.54 vs. $12.82 \%-$, although difference was not statistically significant. Severity of endoscopic findings was associated to need for surgical treatment -severe IC needed surgery in $57.1 \%$ of cases $(n=16)$, moderate in $7.1 \%(n=3)$ and mild in $2,5 \%(\mathrm{n}=1), \mathrm{p}<0.001-$.

Overall mortality was $27.67 \%$. We did not found any association with sex or cardiovascular risk factors. Mortality was associated with a history of recent cardiovascular surgery [56 vs. 19.8\%, $\mathrm{p}=0.001]$, urgent colonoscopy indication [35.6 vs. 12.8\%, $\mathrm{p}=0.01]$, and severity-related findings in colonoscopy [48.38\% in severe vs. $51.61 \%$ in mild/moderate, $\mathrm{p}<0.05]$.

Multivariate analysis demonstrated the association between mortality and the colonoscopy findings (OR 3.49, IC $1.28-9.52, \mathrm{p}<0.05)$ and mortality with recent prior surgery (OR 3.99, IC 1.38-11.49, p < 0.05). Mortality was not associated with urgent indication of colonoscopy (OR 1.67, CI 0.51-5.4, $\mathrm{p}=0.4$ ). 


\section{DISCUSSION}

Ischemic colitis occurs mainly in older patients with cardiovascular disease without gender predilection (1). In our study, incidence was similar in both sexes and mean age of patients was over 70 years. More than half of patients had high blood pressure and prior history of stroke. Moreover, $37.2 \%$ were smokers and more than $20 \%$ had diabetes mellitus and/or dyslipidemia. All this data suggests a relationship between this disease and degenerative changes in the vasculature. However, some authors have found up to $20 \%$ of patients younger than 45 years (2). When it occurs in young patients, it should be considered the existence of risk factors such as hypercoagulable diseases and vasculitis (3), aortic surgery, recent coronary artery bypass (4), cytomegalovirus infections and Escherichia coli 0157: H7 (5), obstructive lesions of the colon such as diverticulitis, volvulus or colorectal cancer, (6), cocaine (7) and iatrogenic causes. It also include a wide variety of drugs such as sumatriptan, estrogen (8), psychotropic drugs, methamphetamine, drugs with vasoconstrictive properties and hypotensive drugs such as digitalis and beta blockers. It also has even been associated with treatment with interferon-alpha and ribavirin for chronic hepatitis HCV (9) and in long-distance runners (10). In our study, 4 patients were under 45 years. Ischemic colitis in three of them was the result of hypotension in the context of septic shock. The other patient was secondary to vasculitis.

IC is caused by decreased vascular flow in the colon as a result of occlusive or nonocclusive events in the territory of mesenteric arteries. Occlusive forms can occur during a stroke (11), thrombosis or trauma (4) -the most typical example is the ligation of inferior mesenteric artery in aortic reconstructive surgery-. Small vessel occlusions usually occur in hypercoagulable states or vasculitis (3). Nonocclusive forms can appear spontaneously in people with vascular risk factors or as a result of vasospasm in situations of low cardiac output secondary to heart failure, hemorrhage, sepsis or dehydration (10). With respect to the IC that occurs after aortic surgery, it has been reported in $3-7 \%$ of cases of elective aortic surgery and in more than $60 \%$ of patients who undergo urgent emergency surgery due to aortic aneurysm broken. In these last patients, overall mortality is $50 \%$ and more than $90 \%$ if there is transmural involvement at diagnosis. For this reason, some authors recommend to make a colonoscopy within 24 hours after resection of an aortic aneurysm broken. Later, if there are early risk factors such as hypotension at admission, prolonged surgical time, sustained hypotension during surgery, metabolic acidosis and prolonged clamping time, it is recommened repeated colonoscopies for early diagnosis and treatment (12). In our study, $22.3 \%$ of patients had a history of recent cardiovascular surgery. Of these patients, $16.96 \%$ underwent to elective aortic vascular surgery which required clamping. In this subgroup, mortality was significantly higher (56vs. 19.8\%, p < 0.05). In patients with ischemic colitis after aortic reconstruction surgery for aortic aneurysm broken mortality was $100 \%$.

IC is more common in the left colon, especially in splenic flexure and rectosigmoid junction, although any area of the colon, including the rectum, may be affected (13).

The most frequent symptom is abdominal pain (in $80 \%$ of cases). It is usually located in the lower left quadrant, with sudden onset, colic pain and maybe accompanied by rectal bleeding or hematochezia (70\%) (13). Signs of peritoneal irritation depending on the severity of colitis or fever and tachycardia can de detected. In severe cases with transmural necrosis, obvious signs of peritonitis (14) and eventually shock can be found. In our study, we observed that IC has rectal bleeding $(56.25 \%)$ and/or abdominal pain $(33.04 \%)$ in most cases. Other forms of presentation less frequent were diarrhea $(5.35 \%)$, anemia (3.57\%) and postoperative fever (1.78\%). Some authors believe that hypertension and history of cancer are risk factors for colonic necrosis (15) but in our study hypertension was not associated with increased need for surgical treatment $(14.7 v s .21,4 \%, \mathrm{p}=0.3)$ nor to higher mortality $(26.1 v s .31 \%, \mathrm{p}=0.5)$.

IC may manifest clinically in two different ways: not gangrenous IC, more frequent (80-85\%), and gangrenous IC $(15-20 \%)$. The last one requires urgent surgery to remove the non-viable colonic mucosa (16). In these cases, signs of intestinal gangrene with or without perforation occur hours after the onset of symptoms. In our study, according to these data, only $25 \%$ of patients were diagnosed of severe ischemic colitis. In these patients, surgical treatment was done in $57.14 \%$. Only $50 \%$ had a good outcome.

Regarding to diagnosis, there is no early serum marker. Abdominal radiography and CT are useful tools to detect upper mesenteric ischemia and complications such as pneumatosis and perforation. In CT, it is possible to detect nonspecific changes such as intestinal wall thickening (17) that allow assessing the extent of the ischemic segment. Doppler ultrasound provides useful information in the diagnosis of IC, especially when it is neccesary to differentiate from the inflammatory bowel disease. In IC, there is absence of vascular flow in the colon wall that let make the diagnosis with specificity between 92 and $100 \%$ (18).

The main diagnostic method is colonoscopy with biopsy (19). In most cases, it is sufficient to examine the first 40 inches to establish the diagnosis. Many typical endoscopic findings have been described (loss of vascularity, erythema, friability, granularity, ulceration, exudate, and submucosal hemorrhage areas), but none of them can be considered as pathognomonic endoscopic finding. The ulcers have been described as longitudinal, serpiginous, elongated or confluent. The sign of "single-stripe" (20) has been strongly associated with mild stages; the linear appearance of this inflammation is due to segmental vas- 
cular compromise. When there is necrosis of the wall, the mucosa has usually cyanotic, greyish or blackish appearance. This implies a severe ischemic event. In these cases, it should be stopped exploration because of the perforation risk. From the histological point of view, macrophages with iron and submucosal fibrosis are characteristic of ischemic injury (21).

In addition, colonoscopy also allows the diagnosis in cases of non-typical presentation, as is the case of patients presenting without abdominal pain or rectal bleeding as occurred in some patients in our study. These events sometimes involve a specific therapeutic approach previously uninitiated. In our study, colonoscopy in patients with ischemic colitis, regardless of severity or presentation, conditioned a change in therapeutic attitude in $50 \%$ of cases. In urgent explorations, this change occurred in more than $65.75 \%$, performing conservative treatment not already begun or performing surgery. Urgent colonoscopy (within 24 hours from the onset of symptoms) diagnosed $85.71 \%$ of the severe forms.

Recent studies (22) show that in patients with severe disease, serial endoscopic and clinical evaluations are the best indicator for surgery before the onset of septic shock, gangrene or perforation. This approach increase survival $(30 \%$ of deaths in patients with surgery after endoscopic or clinical worsening compared with $62 \%$ of deaths in patients with surgery at the onset of peritoneal irritation or shock).

Mesenteric arteriography is indicated in suspected acute mesenteric ischemia. In these cases, it can clarify the diagnosis (stroke, thrombosis or nonocclusive ischemia) and provides the ability to reverse the vasospasm associated with intra-arterial infusion of vasodilating drugs or performing thrombectomy (23).

Regard to treatment, if there are no signs of peritonitis on physical examination, the therapy must be conservative with intravenous administration of fluids and antibiotics (24). It should improve cardiac output and suspending agents that cause mesenteric vasoconstriction. In patients who develop clear signs of peritonitis and those with clinical deterioration, it is neccesary to perform laparotomy with bowel resection (16). In our study, the type of treatment performed was conservative (intravenous fluids and antibiotics) in most cases. Surgical treatment was performed only in 20 patients.

On univariate analysis, we note that neither sex nor any risk factors (hypertension, diabetes mellitus, dyslipidemia, tobacco abuse and prior cardiovascular events) were associated with the need for surgical treatment. Patients with urgent indication for endoscopy needed more frequently surgery, although the result was not statistically significant. Severity of findings on colonoscopy was associated with an increased need for surgical treatment, as surgery was required in severe stage in $57.1 \%$ of cases.

Overall mortality of the IC can be estimated at $8-10 \%$. However, this rate increases to $50-60 \%$ when surgery is required. In our study, overall mortality was 27.67 and
$53.57 \%$ in severe IC stages. In this last group of patients, surgical treatment was performed in 16 patients with good outcome only in $50 \%$ of cases. Mild or moderate IC patients had a better prognosis with a favorable outcome in $80.95 \%$ of cases and with lower need for surgical treatment.

In our serie, neither sex nor any other risk factors were associated with mortality. However, latter was significantly associated with recent history of cardiovascular surgery, urgent colonoscopy indication and with the severity of findings observed in colonoscopy.

Multivariate analysis demonstrated the association of mortality with the staging established by colonoscopy and recent surgery $(\mathrm{p}<0.001)$, not being associated with an indication of urgent exploration.

In conclusion, our study shows that ischemic colitis is more common in older age and affects both sexes equally. The most common symptoms were rectal bleeding and abdominal pain and it is associated with the presence of cardiovascular risk factors and history of recent cardiovascular surgery. Regard to colonoscopy, the severity of colitis is associated with increased need for surgery and higher mortality. The ability of this technique for staging and the later management of patients with suspected ischemic colitis is critical because it allows assessing the severity and a change of attitude as the result of it.

\section{REFERENCES}

1. Green BT, Rendler DA. Ischemic colitis: a clinical review. South Med J 2005; 98: 217-22.

2. Arnott IDR, Ghosh S, Ferguson A. The spectrum of ischaemic colitis. Eur J Gastro Hepatol 1999; 11: 295-303.

3. Kkoutrobakis IE, Sfiridaki A, Theodoropoulou A, Kouroumalis EA. Role of acquired and hereditary thrombotic risk factors in colon ischemia of ambulatory patients. Gastroenterology 2001; 121: 561-5.

4. Maupin GE, Rimar SD, Villalba M. Ischemic colitis following abdominal aortic reconstruction for ruptured aneurysm. A 10 year experience. Ann Surg. 1989; 55: 378-80.

5. Su C, Brandt L, Sigal SH, Alt E, Steinberg JJ, Patterson K, et al. The inmunohistological diagnosis of E. coli 0157: H7 colitis: possible association with colon ischemia. Am J Gastroenterol 1998; 93: 1055-9.

6. Morales García D, Bernal Marco JM, Naranjo Gómez A. Isquemia cólica simulando un carcinoma. Rev Esp Enferm Dig 2005; 97(1): 60-7.

7. Linder J, Monkemuller K, Raijman I, Johnson L, Lazenby AJ, Wilcox CM. Cocaine-associated ischemic colitis. South Med J 2000; 93: 909-13.

8. Charles JA, Pullicino PM, Stoopack PM, Shroff Y. Ischemic colitis associated with naratriptan and oral contraceptive use. Headache 2005; 45(4): 386-9.

9. Leung Y, Urbanski SJ. Ischemic colitis during pegylated interferonalpha and ribavirin therapy for chronic hepatitis C. Can J Gastroenterol 2006; 20(10): 661-3.

10. Lucas W, Schroy PC. Reversible ischemic colitis in a high endurance athlete. Am J Gastroenterol 1998; 93: 2231-4.

11. García Brao I, Mella García E, Rodríguez Martínez E, Bahamonde Calvelo F, Rivas Polo JI, Machuca Santa Cruz J. Cholesterol embolism causing ischemic colitis. Rev Esp Enferm Dig 2008; 100 (5): 305-13

12. Cordobés-Gual J, Riera-Vázquez R, Merino Mairal O, Lara Hernández R, Manuel Rimbau C, Corominas Roura C, et al. Factores predictivos de colitis isquémica después de un aneurisma de aorta abdomi- 
nal roto. Angiología 2004; 56 (5): 459-468.

13. Baixauli J, Kiran RP, Delaney CP. Investigation and management of ischemic colitis. Cleveland Clin J Med 2003; 70: 920-34.

14. Scharffr JR, Longo WE, Vartanian SM, Jacobs DJ, Bahdursingh AN, Kaminski DL. Ischemic colitis: spectrum of disease and outcome. Surgery 2003; 134: 624-30.

15. Barouk J, Gournay J, Bernard P. Ischemic colitis in the elderly: predictive factors of gangrenous outcome. Gastroenterol Clin Biol 1999; 23: 470-4.

16. Pla Martí V, Alos Company R, Ruiz Carmona MD, Solana Bueno A, Roig Vila JV. Experiencia y resultados en el tratamiento quirúrgico y conservador de la colitis isquémica. Rev Esp Enferm Dig 2001; 93: $501-4$

17. Lefkovitz Z, Capbell MS, Lookstein R, Mitty HA, Gerard PS. Radiologic diagnosis and treatment of gastrointestinal hemorrhage and ischemia. Med Clin north Am 2002; 86: 1357-99.

18. Ripollés T, Simo L, Martínez-Pérez MJ, Pastor MR, Igual A, López
A. Sonographic findings in ischemic colitits in 58 patients. AJR 2005; 183: 777-85.

19. Screenarasimhaiah J. Diagnosis and managemente of ischemic colitis. Curr Gastroenterol Rep 2005; 7(5): 421-6.

20. Zuckerman GR, Prakash C, Merriman RB, Sawhney MS, DeSchryver-Kecskemeti K, Clouse RE. The colon single-stripe sign and its relationship to ischemic colitis. Am J Gastroenterol 2003; 98 : 2018-22.

21. Toursarkissian B, Thompson RW. Ischemic colitis. Surg Clin North Am 1997; 77: 461-70

22. Huguier M, Barrier A, Boelle PY. Ischemic colitis. Am J Surg 2006; 192(5): 679-84.

23. Kozuch PL, Brandt LJ. Review article: diagnosis and management of mesenteric ischaemic with an emphasis in pharmacotherapy. Aliment Pharmacol Ther 2005; 21: 201-15.

24. Farber MS, Arams JH. Antibiotics for the acute abdomen. Surg Clin North Am 1997; 77: 1395-417. 